\title{
THE REOPENING OF PULKOVO OBSERVATORY
}

T 1835, F. G. W. Struve was commanded by the 1 Emperor Nicholas to superintend the erection, without regard to expense, of an astronomical observatory at Pulkovo on the summit of the low hills some eleven miles south of St. Petersburg. A broad highway already led due south (actually it is a dogree away from the true meridian) from the Admiralty spire in the centre of the city, and the site chosen was on the line of this road. The Observatory, which "was acknowledged to surpass all others of its kind in splendour, efficiency and completeness", was opened in August 1839 with Struve as director. The renown of the Observatory mainly rests on the incomparable series of meridian observations, made with great skill and care, without interruption and with the same instruments-a transit telescope for right ascensions and a vertical circle for declinations. The value of these observations to positional astronomy is very great. But its fame also rests on a broader basis, especially in later years.

Pulkovo Observatory maintained its standing through the Revolution of 1917 , and its traditional work on fundamental astronomy was continued on a high level until the Second World War. During the siege of Leningrad in 1942, the Observatory was in the direct line of fire, and its site, commanding the plane of the city and clearly of military importance, was occupied by the enemy. The buildings were completely destroyed, but the smaller instruments, the optical parts of the larger instruments and the more valuable records and books (including the Kepler manuscripts) were moved to safety ; among other losses the mounting of the 30 -in. refractor was demolished. At the end of the War the Observatory lay in ruins.

The rebuilt and re-equipped Central Observatory of the Academy of Sciences of the U.S.S.R. at Pulkovo (Fig. 1) was formally inaugurated on May 20-22 in the presence of some five hundred astronomers and scientists, including representatives from most countries from China to the United States. The inaugural address was given on the evening of May 20 in the hall of the Academy of Sciences in Leningrad by Academician Bardin, acting on behalf of the president of the Academy, who was ill. On the following day he declared the Observatory open by formally cutting the tape at the entrance to the main building; this ceremony was followed by the presentation of congratulatory addresses and a general inspection of the Observatory. Many of the addresses were in elaborate

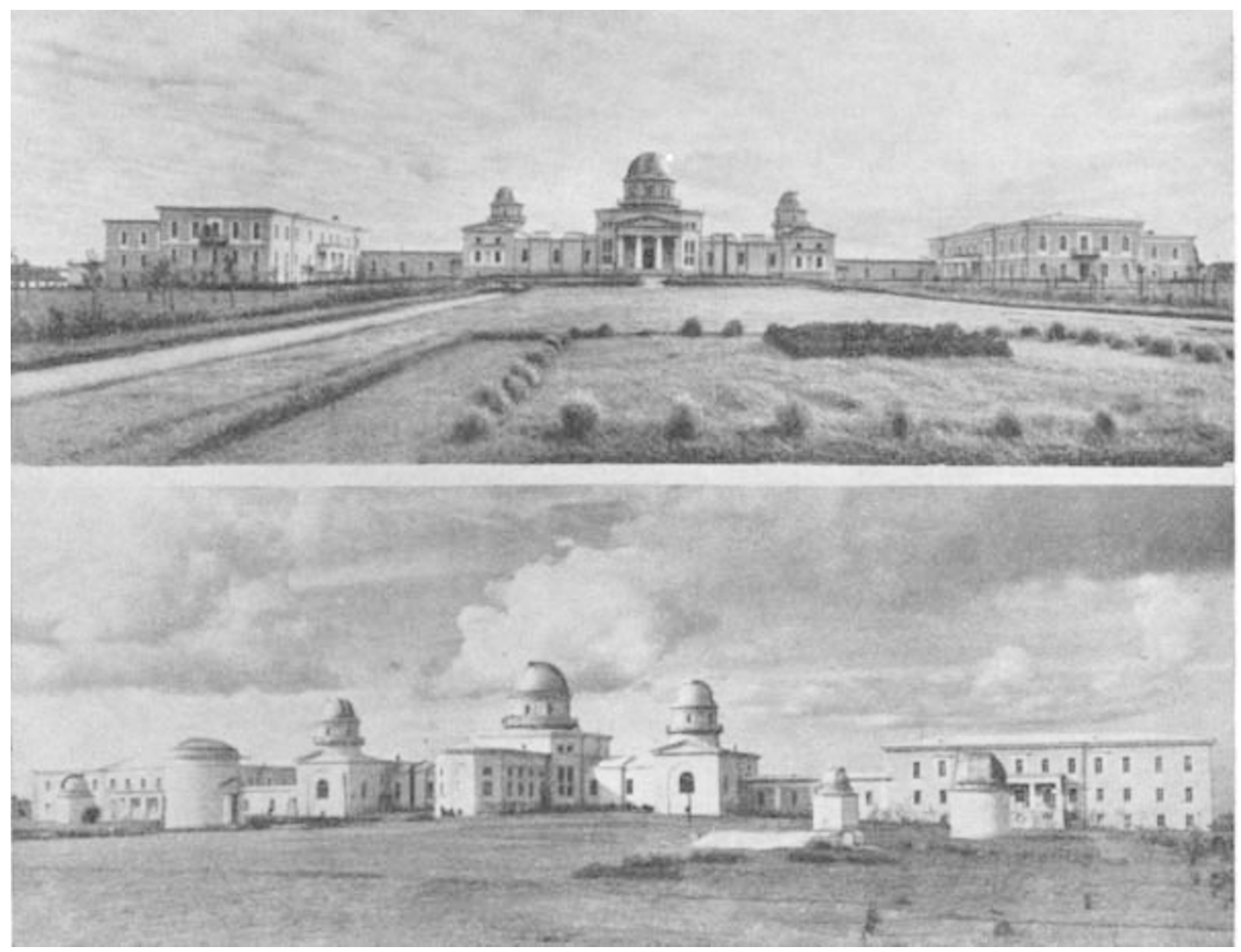

Fig. 1. General views of Pulkovo Observatory: above, from the north; below, from the south 


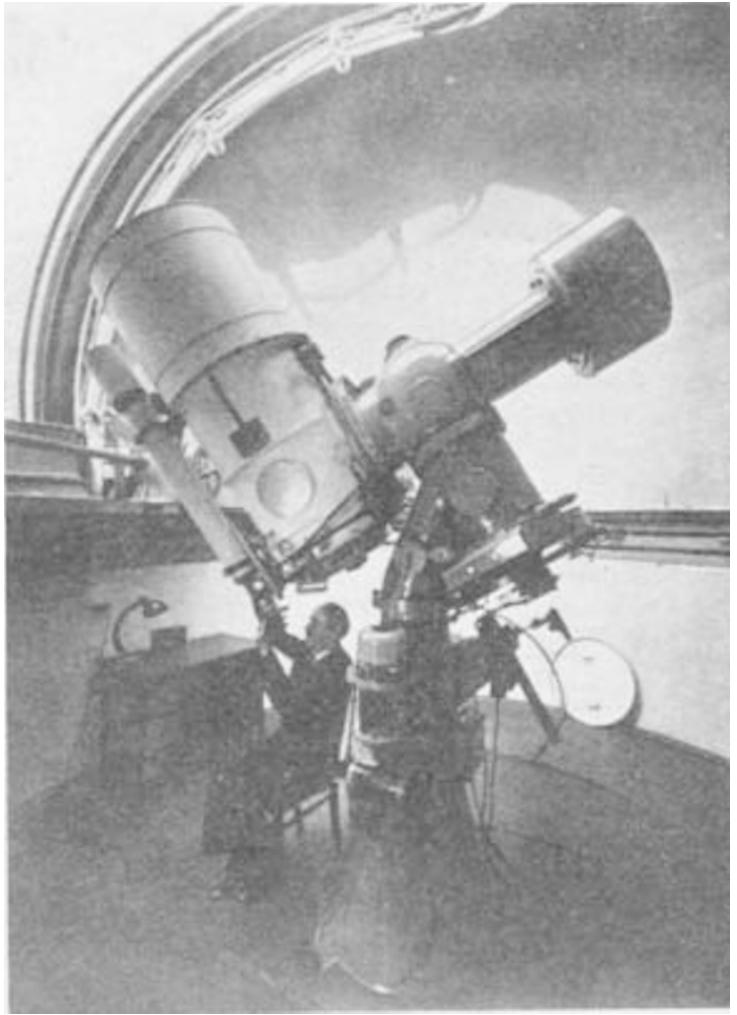

Fig. 2. The Maksutor meniscus telescope. The ultra-violet spectrograph is designed for attachment at the end of the polar axis

bindings, and the Chinese delegation presented a magnificent red and gold silk banner. The following day was devoted to a series of papers describing the work of the Observatory by the astronomers in charge of the different departments.

The main building of the Observatory has been rebuilt exactly as it was (even to the date 1839 over the main entrance), thus preserving the well-known silhouette of the three domes (actually they were turrets in the old building), which is such a fine landmark as seen from Leningrad. But two large wings have been added, containing offices, laboratories, residences for the director and senior staff, and a magnificent conference room; seating more than 250 in tip-up chairs, panelled in marble, with fine curtains, with cinema projectors and screens, it must surely be the finest in any observatory.

In the central building are the two famous old meridian instruments of 1839 , restored and in working condition, side by side with new instruments. One of these is a mir. ror transit in which star passages are observed through fixed northsouth telescopes by reflexion from a steel mirror, which is the only moving part; the results are encouraging. At present the three domes contain only minor instruments or are awaiting new ones.
However, there are some twenty other groups of buildings and domes, a few still in course of erection. The larger buildings comprise a hotel which can accommodate fifty students or guests, living quarters for the staff, and a hostel for junior staff ; there is even a lkindergarten. Some of the domes and pavilions contain the pre-war instruments, such as the 7-in. meridian circle (1914), the astrographs and the vertical telescope ; but there are four or five entirely new instruments. Perhaps the most interesting is the 500-mm. Maksutov meniscus telescope (Fig. 2), designed for use with a spectroscope in the ultraviolet; it appears to have been built entirely in the Soviet Union.

Another remarkable instrument is a polar telescope designed by the director, Prof. A. A. Mikhailov. It must be one of the few telescopes with which observations are made through a glass window ; this allows the whole building to be thermally insulated. The instrument is operated by remote control, so that the observer need not enter the building during the night's observation. Careful measurements show that, by excluding the body-heat of the observer, internal refractions in the telescope tube are substantially reduced; there is a still further reduction when the building is left sealed for several days. For simplicity the plate is fixed, and exposures are made by means of a rotating shutter in front of the object glass ; the position of the pole is therefore determined on each plate from a series of short ares for each of four or five stars. 'The interesting feature is that the Loomis telescope at Yale, adapted for precisely the same programmes, uses an entirely different design : the long tube is open to the outside air, and the plate rotates to counteract the earth's rotation. The eventual comparison of results from the two instruments will indicate which choice of desirable and undesirable factors is the better.

A rather revolutionary instrument is an interferometer (looking like a range-finder) designed by Academician Linnik for observing, with extreme accuracy, the horizontal component of the separation of double-stars (see Fig. 3). By observing at different

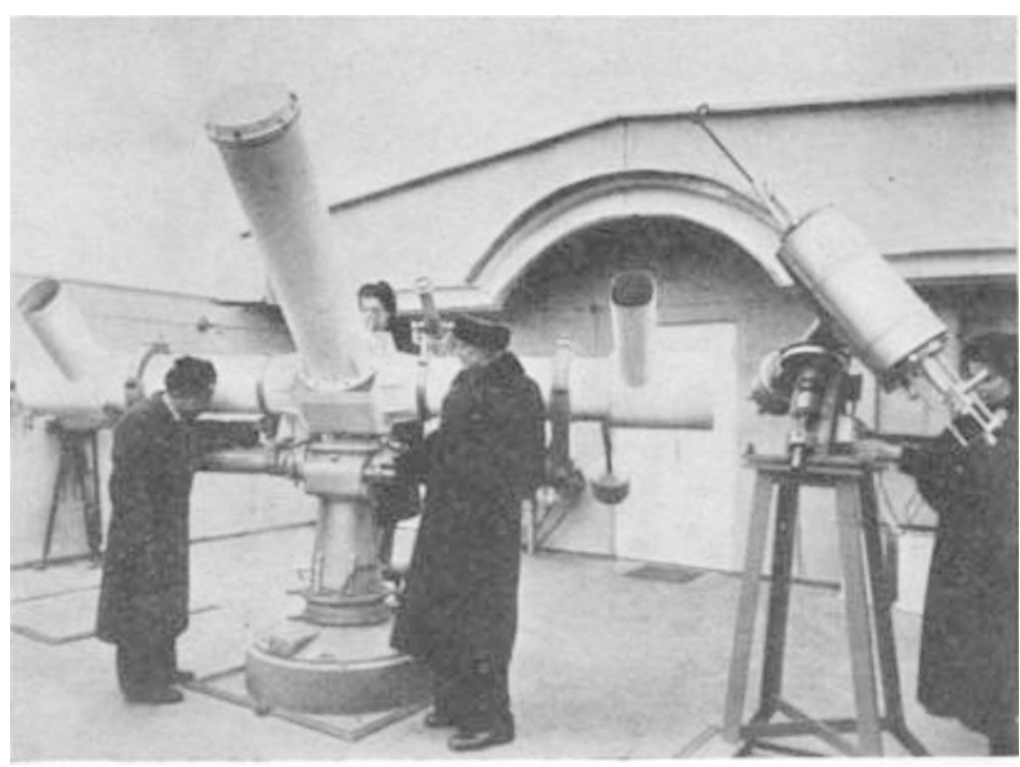

Fig. 3. The Linnik interferometer for measuring the separation of double stars. Academician Iinnik is in the centre of the picture 
hour angles, the actual separation and position angles can thus be calculated.

The horizontal solar telescope with its several different spectrographs is apparently giving good results, due mainly (according to Prof. Krat) to the excellent definition which is a feature of Pulkovo during the early summer. Some of the direct photographs, on a scale of $56 \mathrm{~cm}$. for the sun's diameter, show remarkable surface detail and solar granulation, with individual granules about $0.4^{\prime \prime}$ in diameter.

It has been decided not to remount the 30 -in. object glass, and a new 32 -in. objective has been constructed in Leningrad; a mounting is being designed.

It is impossible to assoss the merit of an observatory, especially one of which the main work is astrometric, from a superficial tour of inspection. To British ideas some of the building work (largely done by women) is rather poor and some of the equipment rather naive. But the general impression is that Pulkovo is a fine observatory, with a wide range of instruments, and, above all, with a first-class staff under the direction of an astronomer who commands world-wide respect; there seems every prospect that Pulkovo will attain the eminence in the future that it has so justly been accorded in the past.

This account would not be complete without recording that the rebuilding of Pulkovo is but one of the many evidences of great astronomical activity in the Soviet Union. For example, the Sternberg Institute and Observatory of the University of Moscow are being rebuilt on a grand scale on the Lenin Hills, in the shadow (as it were) of the towering new university buildings; but the main observing station will be some twenty. five miles south of Moscow. The opening ceremonies were followed by two conferences-one on astrometry and the other on variable stars -both of which were the eleventh of a regular series organized by the Astronomical Council of the Academy of Sciences. The numbers present at these conferences and the reports from the different observatories confirmed the increasing interest in astronomy. Other evidence is the great number of text-books, at all levels, being produced : some are extremely good.

There is not, and perhaps has never been, any doubt as to the genuine desire of the Soviet astronomers themselves to co-operate with those of other countries; the personal contacts at Pulkovo reaffirmed this, and it is greatly to be hoped that freer intercourse will be possible.

The astronomers from the Western countries (two American, one Canadian, two British, two French, one Belgian, two Dutch, one Norwegian, one Swedish and one Italian) are most grateful to the Soviet Academy of Sciences for making possible this meeting with their colleagues in the U.S.S.R., and for its most generous and comprehensive hospitality both in Leningrad and later in Moscow.

\footnotetext{
D. H. SADLER
both in Leningrad and later in Moscow.
}

\section{A GREAT HAUL OF AMBERGRIS BY ROBERT CLARKE}

National Institute of Oceanography, Wormley, Surrey

$\mathrm{D}$ URING the last Antarctic whaling season a boulder of ambergris weighing $926 \mathrm{lb}$. was found in the large intestine of a bull sperm whale (Fig. 1). The whale, which was $49 \mathrm{ft}$. long, was being worked up on board the floating factory Southern Harvester on December 21, 1953, in $58^{\circ} 23^{\prime} \mathrm{S}$., $14^{\circ} 13^{\prime} \mathrm{W}$.

Although this boulder is no doubt the largest single mass to be properly examined and authenticated, the figure of $926 \mathrm{lb}$. is actually exceeded by four others in the literature. However, when these figures are examined, at least three of them do not necessarily refer to a single mass from one whale : the largest figure is to be found in The Times of December 15, 1947, which printed a report that the Brazilian steamer Araxa chanced upon ten tons of ambergris at sea. This was described as a "gray, odoriferous mass" ; but it is not conceivable that such a quantity could have come from one whale, and, if the substance was ambergris and its weight not exaggerated, then it could only have been an extraordinary drift of numerous lumps of flotsam ambergris close together. The other three figures are more reasonable when judged by the present haul. $983 \mathrm{lb}$. of ambergris were entered in the manifest of the whaling bark Splendid of Dunedin, New Zealand, in 1883 ${ }^{1}$; but this was a production figure at the end of a whaling voyage and so may have included ambergris from more than one whale. The Portuguese Fisheries Statisties record $928 \mathrm{lb}$. (422 kgm.) from San Miguel, Azores, in 1944; but this may have comprised a lump of $708 \mathrm{lb}$. (322 kgm.) plus one or more smaller finds ${ }^{2}$. The only figure, in fact, which specifically refers to a single mass of ambergris greater than the present haul is one of $982 \mathrm{lb}$. and describes ambergris 